\title{
El aprendizaje en tiempos de contingencia
}

María de Lourdes Pacheco González y Laura Patricia Ramírez Ramírez

\section{Resumen}

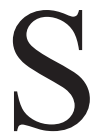

i bien la educación a distancia no es nueva, la contingencia provocada por el coviD-19 llevó a que profesores y estudiantes de la Universidad Autónoma de Aguascalientes dejaran las aulas y recurrieran a la modalidad educativa en línea, para continuar con los cursos. Pero ¿cómo ha sido esta experiencia para los jóvenes bachilleres y universitarios? Ante esta pregunta es que se formuló una encuesta para conocer la experiencia de los estudiantes; los resultados dan cuenta de que a pesar del tránsito a una experiencia en línea ha sido buena, de que ha permitido desarrollar habilidades y actitudes nuevas, así como el desplegar su capacidad de autoaprendizaje, los estudiantes siguen prefiriendo el modelo presencial, donde el trato con los compañeros y con los profesores les permiten comparar opiniones y así modificar o mantener las propias. Esta experiencia ha de llevar a presentar cursos híbridos, donde tanto profesores como estudiantes den lo mejor de sí.

Palabras clave: educación a distancia, escuela tradicional, aprendizaje, competencias, habilidades.

\section{Introducción}

Este 2020 trajo consigo enfrentar una pandemia y con ello también cambiar la manera de interactuar en todos los ámbitos de desarrollo humano, por tanto el de la educación ha tenido que modificar el modo en que se lleva a cabo el proceso enseñanza-aprendizaje (E-A). Si bien la educación a distancia no es nueva, sí es un hecho que la contingencia en que nos encontramos ha provocado que profesores y estudiantes de la Universidad Autónoma de Aguascalientes (UAA) transiten a esta modalidad para poder continuar con los cursos.

La UAA cuenta con la plataforma educativa institucional denominada "Aula Virtual", en la que los profesores pueden proporcionar material, abrir espacios para entrega de tareas o realizar algún otro tipo de actividades que complementen su trabajo presencial; sin embargo, ahora este espacio educativo se ha convertido, junto con otros recursos electrónicos, en su sitio de trabajo.

Es una realidad que esta modalidad para desarrollar competencias académicas ha presentado, en este periodo de contingencia, momentos de éxito, sin descartar las situaciones en las que la plataforma educativa ha fallado debido a la saturación de usuarios; o bien, por las condiciones que los alumnos y, quizá, algunos docentes, han enfrentado ante las consecuencias de la pandemia: motivos de salud, económicos, trastornos emocionales, que les impidan ejercer el proceso educativo a distancia de una manera óptima.

Indudablemente, el uso de plataformas educativas, como con la que cuenta nuestra institución, representa un excelente instrumento para enriquecer la educación académica; facilita tanto al educador como al educando a realizar sus actividades desde la comodidad de su hogar, sin presiones espacio-temporales, esto mediante las actividades asincrónicas, aunque claro, existen, también, otros recursos tecnológicos que permiten las videollamadas para impartir clases, incluso a grupos numerosos de alrededor de 50 personas; resaltando que no todas las personas pueden ingresar a esta actividad a distancia sincrónica, por fallas en la red, en la instalación de programas, incluso (aunque en el mínimo de los casos) por carencia de equipos electrónicos que permitan este modo interactivo en la educación.

Fecha de recepción: 24 de julio de 2020 Fecha de aceptación: 25 de septiembre de 2020 Fecha de última actualización: 6 de noviembre de 2020 


\section{Educación a distancia en el siglo XXI}

Durante mucho tiempo se mantuvo el perfil de una escuela tradicional compuesta por un espacio físico a donde acuden tanto alumnos como profesores, siendo este último la fuente de conocimiento y el alumno debía aprender de memoria. Sin embargo, las cosas han cambiado y ahora no sólo se habla de una sociedad del conocimiento, ${ }^{1}$ sino también de una escuela del siglo xxI; y si bien sigue prevaleciendo el espacio físico, otras imágenes preconcebidas de los procesos de enseñanza y aprendizaje han cambiado, por ejemplo:

- El profesor no es la única fuente de conocimiento.

- El profesor adquiere la figura de guía o facilitador del conocimiento.

- El alumno deja de ser pasivo para convertirse en un agente activo.

- El alumno tiene otras fuentes de información además del profesor, entre otras.

Actualmente, la enseñanza y el aprendizaje han cambiado, ya no se trata de "procesos bancarios", ${ }^{2}$ sino de procesos donde se deben procurar:

- La adquisición de conocimientos y el desarrollo de habilidades.

- La promoción del trabajo colaborativo.

- El desarrollo de competencias.

- La incorporación de dispositivos móviles como recurso escolar y fuente de conocimiento.

Por lo anterior, se ha tenido que adaptar el concepto de enseñanza y aprendizaje para transitar a una educación liberadora que procure el diálogo, la participación del educando y así llegar a un aprendizaje significativo y con ello se alcance "la solución de problemas reales del entorno natural y social" (UAA, 2007, p. 11), uno de los tantos rasgos mencionados en el Modelo Educativo Institucional (MEI). Ante esto es que algunos profesores han ido cambiando su metodología de trabajo y sus recursos didácticos con la intención de dejar atrás el modelo ban-

1 Para la Organización de los Estados Americanos (OEA), la sociedad del conocimiento es necesaria "para competir y tener éxito frente a los cambios económicos y políticos del mundo moderno. [;][...] está bien educada, y se basa en el conocimiento de sus ciudadanos para impulsar la innovación, el espíritu empresarial y el dinamismo de su economía" (OEA, 2020).

2 Paulo Freire es quien utiliza este concepto, refiriendo con él que el estudiante es depositario de los conocimientos depositados por el profesor. cario, y con ello incorporar otros modelos educativos; no obstante, la contingencia a la que nos enfrentamos propició -como única opción- la construcción de un modelo educativo a distancia, ${ }^{3}$ donde tanto profesores como alumnos son nuevos en el manejo de estos recursos, pero sobre todo donde se han enfrentado a un proceso E-A que tiene que ser adaptado y entendido de forma diferente, por más que ya se esté en una educación liberadora.

¿Cómo ha sido esta experiencia para los jóvenes bachilleres y universitarios? Para dar respuesta a esta interrogante, se realizó una encuesta a estudiantes tanto de nivel medio superior como superior, y a continuación se dan a conocer los resultados obtenidos.

\section{Encuesta: "El aprendizaje en tiempo de contingencia"}

Para la realización de este artículo se generó la encuesta denominada: "El aprendizaje en tiempo de contingencia", haciendo uso de Microsoft Forms, de la suite Office 365 , la cual fue respondida por estudiantes de la UAA, tanto de educación media superior como de educación superior de diversos semestres y carreras.

Gráfica 1. Experiencia en la transición a la educación a distancia

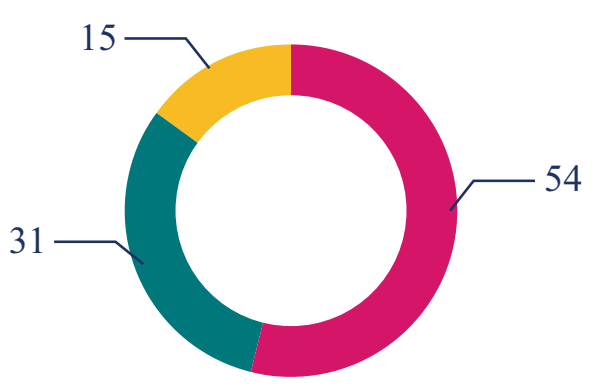

Buena Mala Da igual

Fuente: elaborada por las autoras, 2020.

Este sondeo se compone de nueve preguntas, las primeras dos se refieren al grupo etario y al tipo educati-

3 Ésta se concibe como un "proceso de aprendizaje en el que dos o más personas que se encuentran geográficamente alejados, realizan actividades de enseñanza y aprendizaje, apoyadas por una estructura orgánica y estableciendo comunicación a través de medios de telecomunicación. Modalidad educativa en la que el alumno tiene acceso remoto a las actividades académicas por medio de tecnología, por ejemplo, redes computacionales, internet, videoconferencia, etc." (Secretaría de Educación Pública [SEP], s.f.). 
vo; el resultado para esta parte del formulario indica que fue respondido por un total de 373 estudiantes, oscilando entre las edades de 15 y 23 años; de los cuales 173 corresponden a nivel medio superior y 200 a nivel superior.

En la pregunta número tres se planteó, ¿cómo ha sido la experiencia al transitar de la escuela tradicional a la educación a distancia?, y fue respondida de la siguiente manera: para $54 \%$ de los estudiantes la experiencia ha sido buena, para $31 \%$ mala, y $15 \%$ le da igual.

Para complementar la pregunta anterior, en la cuestión número cuatro se les solicitó que describieran brevemente la experiencia referida en la misma. Los que valoraron como "buena" la experiencia, argumentaron: el hecho de salir de su área de confort y experimentar nuevas áreas de estudio, desarrollando nuevas habilidades. Quienes externaron que su experiencia no ha sido favorable, arguyen principalmente las fallas que ha presentado el aula virtual institucional o la red de internet particular; así como la necesidad que tiene su profesión por trabajar de manera presencial, ya sea por las prácticas de laboratorio o por tener que practicar en conjunto. Los estudiantes que respondieron a la opción "te da igual", comentaron que por una parte se pierde al diálogo y con ello la oportunidad de intercambiar opiniones; pero por otra, llegan a una comprensión más personal, sobre todo sin la influencia de la opinión de los profesores; sin embargo, también hubo aquellos que aludieron el que se perdía la noción entre horario escolar y el resto del día, esto por la gran cantidad de actividades que dejaban algunos de los profesores.

En la pregunta número cinco se les cuestionó si el trabajo en aula virtual les ha permitido construir conocimientos, así como desarrollar habilidades y actitudes, y que justificaran su respuesta. El 49\% de los estudiantes respondieron afirmativamente, sin embargo, la construcción de conocimientos queda desplazada y se centran en el desarrollo de habilidades y actitudes, siendo mencionadas mayormente la paciencia, la organización, la administración de tiempo y el uso de programas para realizar las tareas solicitadas. Para 14\%, el trabajo en aula virtual no les ha ayudado, consideran que es monótono, no hay retroalimentación, solamente se usa para subir tareas, y mencionan el uso de Teams como el medio con el que tienen clases. Finalmente, la justificación del restante $37 \%$ tiene la forma de un "sí, pero...", ya sea por el tipo de materia, la disposición del profesor para ayudar a disipar dudas o bien porque han desarrollado habilidades y adquirido conocimientos, pero prefieren las clases presenciales.

En la pregunta número seis de la encuesta, se solicitó a los estudiantes que justificaran su respuesta, de acuerdo a su consideración si es que la educación en línea les permite adquirir saberes y competencias para enfrentar problemas reales de su cotidianidad; a lo que $48 \%$ respondieron de manera afirmativa, aludiendo a que la universidad actuó acorde a lo que la situación implicó, y que los cursos se han adaptado a ello. El 26\% de los encuestados respondieron negativamente, justificando que el estar en casa no permite saber lo que está ocurriendo realmente; motivo por el que no pueden desarrollar saberes ni competencias. El 25\% respondieron: "sí, pero..."; argumentando que ni profesores ni estudiantes estaban preparados, completamente, para esta modalidad educativa virtual.

Gráfica 2. Educación a distancia ha permitido adquirir saberes y competencias para enfrentar problemas reales de la cotidianidad

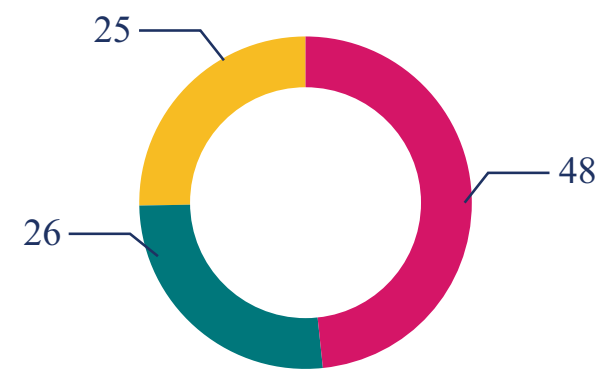

$$
\begin{gathered}
\text { Afirmativamente } \quad \text { Negativamente } \\
\square \text { Si, pero... }
\end{gathered}
$$

Fuente: elaborada por las autoras, 2020.

La pregunta número siete de la encuesta cuestiona acerca de las habilidades que han desarrollado con base en la educación en línea, para ello se recuperaron las habilidades enunciadas por Bloom y que recientemente han sido retomadas y analizadas para la era digital. Siendo así que las habilidades de orden superior (aplicar y analizar) son las competencias que $42 \%$ de los encuestados confirmaron como las que más han llevado a la práctica en esta modalidad educativa; $33 \%$ consideró que han desarrollado las habilidades de orden inferior (recordar y comprender) y que permiten la adquisición de conocimiento, como si las clases en línea estuvieran diseñadas sólo como manera de repaso educativo; mientras que $24 \%$ documentó que las habilidades que más han desarrollado son las de evaluar y crear habilidades de pensamiento de orden superior, que ayudan en la creación de conocimiento en este periodo de contingencia. Bajo esta perspectiva, $66 \%$ de los que participaron en este cuestionario han desarrollado habi- 
lidades de orden superior, lo cual refleja que a pesar de la premura con la que se hizo el cambio de la educación tradicional a la modalidad a distancia, como única opción, se han podido cumplir con los objetivos planteados en los programas de materia.

De acuerdo con la cuestión número ocho de esta encuesta, $46 \%$ de los estudiantes aseguran que las competencias más favorecidas con el trabajo en aula virtual ha sido el tratamiento de la información; esto resulta congruente debido a la manera autodidacta a la que han tenido que enfrentarse en sus estudios ante la educación virtual; mientras que $17 \%$, únicamente confirman que han desarrollado las competencias lingüísticas; siendo así $37 \%$ que respondieron que tanto las competencias de hablar, escuchar, leer y escribir, se han combinado con el tratamiento de la información. Definitivamente hay que desarrollar las competencias lingüísticas de leer y escuchar para poder tratar la información.

Para cerrar con la encuesta, en la pregunta número nueve se les solicitó indicaran el tipo de aprendizaje que ha prevalecido; siendo así que $46 \%$ de los estudiantes consideraron que el aprendizaje individual es en el que se han basado, para realizar exitosamente sus actividades académicas en línea; $13 \%$ documentó el aprendizaje colaborativo; mientras que $41 \%$ destacan la combinación de ambos tipos de trabajo educativo virtual. Cabe destacar que el porcentaje de quienes aseguraron la fusión entre el trabajo individual como el colaborativo resalta la importancia de la función tanto del educando como del educador de buscar que, a pesar de la distancia, se siga dando el trabajo entre compañeros, aún y cuando el trabajo individual es el que despunta.

\section{Conclusiones}

Definitivamente la educación en línea ha permitido continuar con la educación académica en medio de esta contingencia, y ha favorecido en gran medida el desarrollo de nuevas habilidades para todos los integrantes del sistema educativo; ya que se han desarrollado competencias e implementado actividades didácticas que permiten la adquisición de nuevos saberes en el ámbito de la enseñanza y del aprendizaje.

Como mencionan Luis Vargas, Marcela Gómez y Luisa Gómez (2013), las tecnologías de la información y comunicación (TIC) en la educación se ajustan a las exigencias y necesidades de la comunidad educativa. Resulta importante señalar la adecuación de la planeación para crear materiales y buscar los recursos adecuados de acuerdo al contenido de las materias impartidas; ya que, aunque la premura del cambio a la educación distancia como único medio, ha implicado el desarrollo de competencias y habilidades académicas tanto en profesores como en estudiantes; pero dando lo mejor de sí, viéndolo como una oportunidad de aprendizaje y de crecimiento. Sin duda, a partir de esta vivencia los profesores se darán la oportunidad de planear cursos híbridos, mejorar sus materiales y proporcionar óptimo seguimiento al sistema de formación educativa virtual. En cuanto a los estudiantes, también deben ajustarse a las nuevas formas de aprendizaje.

Finalmente, en consecuencia y a diferencia del modo tradicional o presencial de la educación, es considerable reconocer que en pleno siglo XXI, cuando la tecnología se manifiesta en un elevado nivel, hay ámbitos como el académico que no se muestran $100 \%$ favorecidos con dichos avances. Sería ideal una educación en ambientes combinados, aunque claro, cuando las condiciones de salud sean óptimas para la sociedad.

\section{Fuentes de consulta}

Churches, A. (2009). Taxonomía de Bloom para la era digital. Universidad ICESI. Recuperado el 13 de junio 2020, en $\mathrm{http} / / /$ eduteka.icesi.edu.co/articulos/TaxonomiaBloomDigital

OEA. (s.f.). Temas: Sociedad del conocimiento. Recuperado el 8 de julio 2020, en http://www.oas.org/es/temas/sociedad_conocimiento.asp

SEP. (s.f.) Glosario de educación superior. México: SEP. Recuperado el 25 de mayo de 2020, en http://bitly.ws/ameM.

UAA. (2007). Modelo Educativo Institucional, en Correo Universitario, sexta época, No. 16, 15 de marzo de 2007. México: UAA. Recuperado el 25 de mayo 2020, en https://bit.ly/30ghjSW

Vargas, L., Gómez, M., \& Gómez, R. (2013). Desarrollo de habilidades cognitivas y tecnológicas con aprendizaje móvil. Revista de Investigación Educativa, (6), 30-39. Escuela de Graduados en Educación. Recuperado el 7 de julio 2020, en http://bitly.ws/amiU 